Saudi Journal of Medical and Pharmaceutical Sciences

Abbreviated Key Title: Saudi J Med Pharm Sci

ISSN 2413-4929 (Print) |ISSN 2413-4910 (Online)

Scholars Middle East Publishers, Dubai, United Arab Emirates

Journal homepage: http://scholarsmepub.com/sjmps/

Case Report

\title{
Facial Paralysis Caused By an Unusual Parotid Tumor: Facial Nerve Schwannoma A Case Report
}

\author{
Lassikri Omar ${ }^{1 *}$, Bencheikh Razika ${ }^{2}$, Messoudi Lina ${ }^{1}$, Cherradi Nadia ${ }^{3}$, Benbouzid Mohamed Anas ${ }^{2}$, Essakalli Leila ${ }^{2}$ \\ ${ }^{1}$ Resident Physician in Otorhinolaryngology, Department of Otorhinolaryngology, Head and Neck Surgery, Ibn Sina University Hospital, Faculty of \\ Medicine, Mohammed V University, Rabat, Morocco \\ ${ }^{2}$ Professor of Otorhinolaryngology, Department of Otorhinolaryngology, Head and Neck Surgery, Ibn Sina University Hospital, Faculty of Medicine, \\ Mohammed V University, Rabat, Morocco \\ ${ }^{3}$ Professor of Pathological Anatomy, Department of pathological anatomy, Ibn Sina University Hospital, Faculty of Medicine, Mohammed V \\ University, Rabat, Morocco
}

DOI: $10.36348 /$ sjmps.2019.v05i12.018

| Received: 06.12.2019 | Accepted: 13.12.2019 | Published: 30.12.2019

*Corresponding author: Lassikri Omar

\section{Abstract}

Facial nerve schwannoma is an uncommon benign tumor, which is rarely encountered in the parotid gland, and mimicking the tumors of this gland. It's a neurogenic lesion that arises from Schwann cells of peripheral nerve sheath. Most of cases, it is localized in the intratemporal segment of the facial nerve, only $9 \%$ that occur in the extratemporal segment. Intraparotid facial nerve schwannoma was firstly described by Ibarz in 1927. Even if the tumor arises from the nerve itself, the function of the facial nerve is generally unaffected. If there is facial paralysis, it is interfered with malignant parotid tumors. Because of the heterogeneity of imaging features, it is difficult to diagnosis and differentiate preoperatively the intraparotid facial nerve schwannoma from other parotid tumors, so the definitive diagnosis is made by histological examination of resected tumor. The management of intraparotid facial nerve schwannoma is a very contested issue within the literature. Because the benignity and low evolutionary potential of the tumor, some authors advocating a conservative attitude with clinical surveillance for patients without facial nerve dysfunction or for tumor localized in the parotid gland. However, if a severe or a sudden facial nerve dysfunction, or extension into the mastoid was founded, the surgical resection of the tumor is indicated without delay. We report a case of a 24 -year-old young female, complaining of a slow-growing and painless mass in the left parotid area, associated with grade $\mathrm{V}$ facial paralysis on left side since 10 years. No lymphadenopathy was founded in the neck. The computed tomography scan was revealed a heterogeneous tumor, involving in superficial and deep lobes of the left parotid gland, and extending into the parapharyngeal space. On surgical exploration, the dissection of facial nerve and isolation of the mass was impossible. Because the patient had a facial paralysis preoperatively, we had to sacrifice the facial nerve to remove the tumor by total parotidectomy for definitive diagnosis and treatment. The tumor was histopathologically confirmed to be schwannoma of facial nerve in the left parotid gland. The purpose of this study is to highlight the rarity of intra-parotid facial nerve schwannoma occurrence, its clinical features, and the difficulties of diagnosis and management, with review of the literature.

Keywords: Schwannoma, intra-parotid, Facial nerve paralysis, preoperative diagnosis, Surgical management.

Copyright @ 2019: This is an open-access article distributed under the terms of the Creative Commons Attribution license which permits unrestricted use, distribution, and reproduction in any medium for non-commercial use (NonCommercial, or CC-BY-NC) provided the original author and source are credited.

\section{INTRODUCTION}

The tumors of salivary glands account for $3 \%$ to $10 \%$ of all head and neck neoplasms [1]. The parotid tumors constitute $80 \%$ of salivary glands tumors, and $80 \%$ of these tumors are benign $[2,3]$. Among these benign tumors, we find the intra-parotid facial nerve schwannoma, which is usually appearing as a parotid mass. Facial nerve schwannomas is an uncommon benign tumor, which is rarely encountered in the parotid gland, with an incidence ranging from $0.2 \%$ to $1.5 \%$ [4]. Even if the tumor arises from the nerve itself, the function of the facial nerve is generally unaffected [5]. The incidence of facial nerve paralysis is approximately $20 \%$ of cases $[6,7]$. The purpose of this study is to highlight the rarity of facial nerve schwannoma occurrence, and its clinical features, and difficulties of diagnosis and management, with the review of the literature.

\section{CASE REPORT}

We report a case of a 24-year-old young female, without pathological antecedent, complaining of a slow-growing and painless mass in the left parotid 
area, associated with a progressive facial asymmetry with left facial weakness, since 10 years.

On physical examination, we showed a left parotid mass measuring $5 \times 4 \mathrm{~cm}$, soft, partially mobile, and covered with normal skin, associated with grade $\mathrm{V}$ facial paralysis on left side. No lymphadenopathy was founded in the neck. The computed tomography scan was revealed a heterogeneous tumor measuring 50x30 $\mathrm{mm}$, involving in superficial and deep lobes of the left parotid gland, with heterogeneous contrast enhancement, and extending into the parapharyngeal space (Figure-1). No lymphadenopathy was detected in the neck. On surgical exploration in the left parotid gland, we founded an encapsulated and yellow mass which is in close relationship with the main trunk of facial nerve.
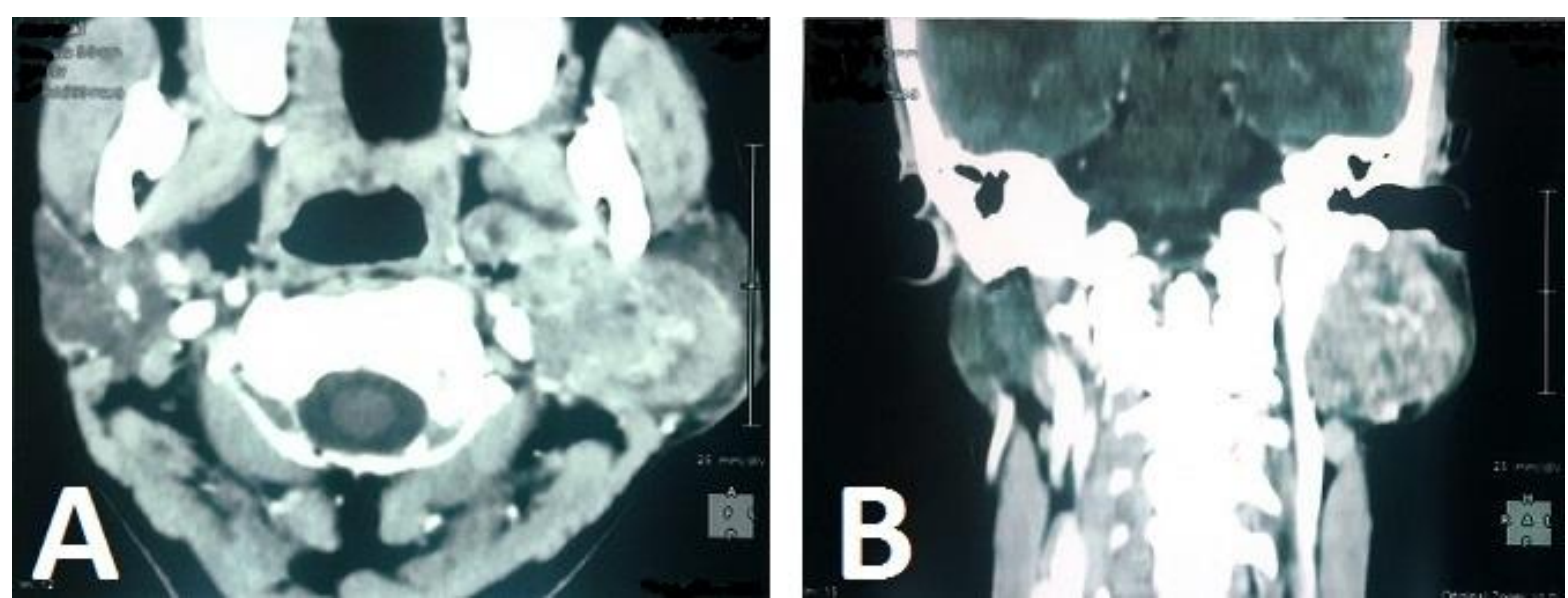

Fig-1: Axial (A) and coronal (B) images of CT scan, showing a heterogeneous lesion involving in superficial and deep lobes of the left parotid gland, and extending into the parapharyngeal space

The result of the extemporaneous examination was reported as a proliferation of spindle cells with inflammatory cells, and without cytological sign of malignancy.

The tumor could not be separated from the main trunk of facial nerve, so the dissection of facial nerve and isolation of the mass was difficult. Because the patient had a facial paralysis preoperatively, we had to sacrifice the facial nerve to remove the tumor by total parotidectomy for definitive diagnosis and treatment.
Histopathological examination was revealed an encapsulated tumor with spindle cell proliferation; and an alternance of hypocellular areas, and hypercellular palissade areas with Verocay body formation (Figure-2), associated with eosinophilic cytoplasms, and with hyalinised blood vessels. The nuclei are elongated with a few mitoses. The parotid tissue was normal. There was no necrosis, or atypia. So the tumour was histopathologically confirmed to be schwannoma of facial nerve in the left parotid gland.
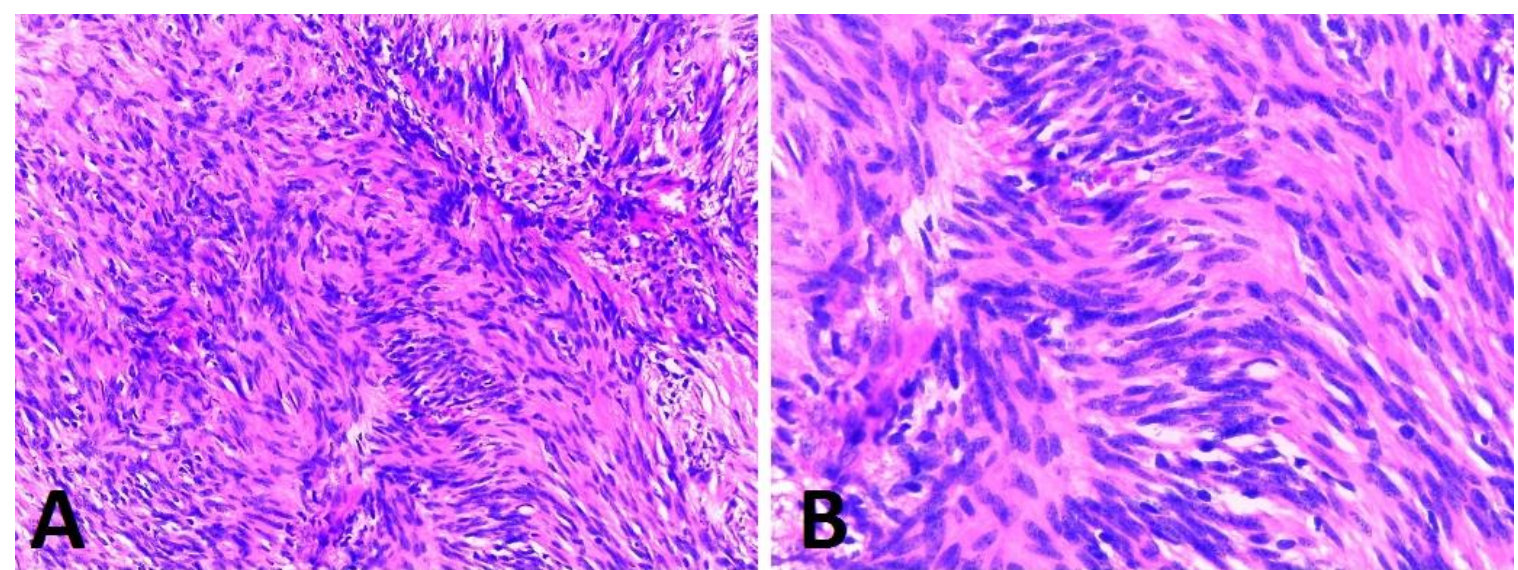

Fig-2: Cytology of Facial Nerve Schwannoma, showing spindle cells proliferation, with palisade arrangement forming verocay bodies [hematoxylin-eosin (A) x20; (B) x40]

\section{DISCUSSION}

Facial nerve schwannomas (FNS) is a rare and benign tumor, which is rarely encountered in the parotid gland. It's a neurogenic lesion that arises from Schwann cells of peripheral nerve sheath. It can occur at any part of seventh cranial nerve, from the cerebello-pontine angle to the terminal branches of the face [8]. Most of FNS are localized in the intratemporal segment of the 
facial nerve, only $9 \%$ of cases that occur in the extratemporal segment $[9,10]$. It is rarely encountered in the parotid gland with a frequency ranging from $0.2 \%$ to $1.5 \%$ of all parotid tumors $[4,11,12]$.

Intraparotid facial nerve schwannoma was firstly described by Ibarz in 1927. Often its presentation is nonspecific as a slow growing, mobile, and painless parotid mass [13], mimicking the tumors of the parotid gland. Even if the tumor arises from the nerve itself, the function of the facial nerve is generally unaffected [5]. The incidence of facial nerve paralysis is approximately $20 \%$ of cases $[6,7]$, owing to compression the axons of the nerve. If there is facial paralysis, it is interfered with malignant parotid tumors. In our case, because we have a facial paralysis, the principal differential diagnosis, was the Adenoid cystic carcinoma, which is a malignant tumor that has the potential to spread along the facial nerve sheath [21]. Preoperatively it is difficult to diagnosis and differentiates the intraparotid FNS from other parotid tumors, because its low prevalence and very few typical clinical and radiological signs associated with it. On Ultrasonography, schwannoma appear as a cystic mass with internal septations $[14,15]$. On computed tomography scan, the appearance of schwannoma in the parotid, is a smooth and well circumscribed lesion; and it may revealed the osseous changes [16]. The MRI with gadolinium injection still the study of choice for imaging of the parotid for nerve lesions [17]. In FNS it shows a well-circumscribed mass with signal intensity isointense to muscle on $\mathrm{T} 1$, and hyperintense to muscle on T2 sequence [16]. On T2-weighted images the target sign which is characterized by hyperintensity in the periphery while, and hypointensity in the centre, is suggestive of a FNS [18]. However, these findings may be founded in other neurogenic tumors, such as neurofibroma, and malignant peripheral nerve sheath tumor [19].

The heterogeneity of imaging features and the resulting differential diagnosis, make it difficult to differentiate a FNS from other parotid tumors, such as pleomorphic adenoma, Warthin's tumor, cystadenoma, and parotid duct cysts, that have the same features on imaging [20], and leading to very low rates of preoperative diagnosis [10]. The malignant tumors are hypointense on T2-weighted images, with ill-defined limits [22].

Intraoperatively, the features of intra-parotid FNS are the strong adhesions between the tumor and the facial nerve, so in surgical resection it can be impossible to find a clear surgical plane to dissect the facial nerve and its main trunk [13]. In these cases a facial nerve sacrifice with nerve grafting is necessary. In our case because the tumor could not be separated from the main trunk of facial nerve, and because the patient had a facial paralysis preoperatively, we had to sacrifice the facial nerve to remove the tumor by total parotidectomy for definitive diagnosis and treatment.
The intraoperative frozen section examination is recommended for both diagnosis and excluding malignancy [23], however the definitive diagnosis of FNS in parotid gland is made by histological examination of resected tumor [13]. The macroscopic appearance of Schwannomas is an encapsulated, soft and white, yellow, or pink tumor. Their capsule is continuous with nerve sheath [24]. Histologically, schwannoma is composed of a biphasic tissue architecture, which is founded in the same tumor: The hypercellular Antoni A area with Verocay bodies [25], which is characterized by the presence of elongated and spindle-shaped Schwann's cells, and their nuclei are aligned in a palisading pattern. And the hypocellular Antoni B area, which has a varying degree of cell pleomorphism, with irregular cell scattered in loose connective tissue, and there is no definable palisading of tumor cells nuclei. The Nerve fibers are not part of the tumor, because the tumor arises from Schwann's sheath [26]. On immunohistochemistry, the S-100 staining will be strongly positive [7] and the Ki-67 proliferative index will be less than $1 \%$. The calretinin staining can be helpful to distinguish schwannoma from neurofibroma, which may also arise from peripheral nerves (schwannoma will stain diffusely, while neurofibroma will stain focally and weakly) [27].

The management of intraparotid FNS is a very contested issue within the literature. Because the benignity and low evolutionary potential of the tumor, some authors advocating a conservative attitude with clinical surveillance, for patients without facial nerve dysfunction, or for tumor localized in the parotid gland without intratemporal extension [10]. However, if a severe, or a sudden facial nerve dysfunction, or extension into the mastoid was founded, the surgical resection of the tumor is indicated without delay $[28,5$, 29].

\section{CONCLUSION}

Facial nerve schwannoma of parotid gland is a benign, and extremely rare tumor, mimicking the tumors of the parotid gland. Although facial paralysis is more common in malignant tumors of the parotid gland, it can also be founded in cases of facial nerve schwannoma, which is a benign tumor.

The preoperative diagnostic imaging, usually provides no valuable information to determine whether the tumor is originated from the parotid gland, or the facial nerve.

Because the difficulty of preoperative diagnosis, intraparotid facial nerve schwannoma should be suspected, if there is an history of slow gradual facial paralysis, associated with a slow growing parotid mass, without lymphadenopathy, and if facial nerve can not be found in surgical resection; in order to ensure 
adequate management, and generate the best functional outcome for the patient.

Conflicts of Interest: The authors do not declare any conflict of interest.

Contributions of the Authors: All the authors contributed to the realization of this work.

\section{REFERENCES}

1. Ansari, M. H. (2007). Salivary gland tumors in an Iranian population: a retrospective study of 130 cases. Journal of Oral and Maxillofacial Surgery, 65(11), 2187-2194.

2. Eveson, J. W., \& Cawson, R. A. (1985). Salivary gland tumours. A review of 2410 cases with particular reference to histological types, site, age and sex distribution. The Journal of pathology, 146(1), 51-58.

3. Spiro, R. H. (1986). Salivary neoplasms: overview of a 35-year experience with 2,807 patients. Head \& neck surgery, 8(3), 177-184.

4. Patil, P. R., Kulkarni, P. P., \& Ansari, S. A. (2012). Intraparotid Facial Nerve Schwannoma in Childhood: A Case Report. International Journal of Oral \& Maxillofacial Pathology, 3(4), 44-47.

5. Fyrmpas, G., Konstantinidis, I., Hatzibougias, D., Vital, V., \& Constantinidis, J. (2008). Intraparotid facial nerve schwannoma: management options. European Archives of Oto-RhinoLaryngology, 265(6), 699-703.

6. Bretlau, P., Melchiors, H., \& Krogdahl, A. (1983). Intraparotid neurilemona. Acta otolaryngologica, 95(1-4), 382-384.

7. Marchioni, D., Ciufelli, M. A., \& Presutti, L. (2007). Intraparotid facial nerve schwannoma: literature review and classification proposal. The Journal of Laryngology \& Otology, 121(8), 707712.

8. Symon, L., Cheesman, A. D., Kawauchi, M., \& Bordi, L. (1993). Neuromas of the facial nerve: a report of 12 cases. British journal of neurosurgery, 7(1), 13-22.

9. Shimizu, K., Iwai, H., Ikeda, K., Sakaida, N., \& Sawada, S. (2005). Intraparotid facial nerve schwannoma: a report of five cases and an analysis of MR imaging results. American journal of neuroradiology, 26(6), 1328-1330.

10. Gross, B. C., Carlson, M. L., Moore, E. J., Driscoll, C. L., \& Olsen, K. D. (2012). The intraparotid facial nerve schwannoma: a diagnostic and management conundrum. American journal of otolaryngology, 33(5), 497-504.

11. Vellin, J. F., Mom, T., Kemeny, J. L., Essamet, W., \& Gilain, L. (2003). Schwannome du nerf facial intraparotidien: À propos d'une observation. In Annales d'oto-laryngologie et de chirurgie cervico-faciale; 120(4):231-236.
12. Chiang, C. W., Chang, Y. L., \& Lou, P. J. (2001). Multicentricity of intraparotid facial nerve schwannomas. Annals of Otology, Rhinology \& Laryngology, 110(9), 871-874.

13. Gennaro, P., Nastro Siniscalchi, E., Gabriele, G., \& Cascone, P. (2012). Trigeminal and facial schwannoma: a case load and review of the literature. Eur Rev Med Pharmacol Sci,16(4 Suppl), 8-12.

14. Patil, V., Patil, S., Ichalakaranji, R., Biradar, H., \& Ragate, A. (2014). Intraparotid facial nerve schwannoma: A rare case report. International Journal Biomed Advanced Research. 5(9):62-63.

15. Jaiswal, A., Mridha, A. R., Nath, D., Bhalla, A. S., \& Thakkar, A. (2015). Intraparotid facial nerve schwannoma: A case report. World Journal Clinical Cases. 3(3):322-326.

16. Gritzmann, N., Rettenbacher, T., Hollerweger, A., Macheiner, P., \& Hübner, E. (2003). Sonography of the salivary glands. European radiology, 13(5), 964-975.

17. Gibavičienè, J., \& Čepulis, V. (2012). Intraparotid facial nerve schwannoma: a case report. Acta Medica Lituanica. 19(4):445-449.

18. Jäger, L., \& Reiser, M. (2001). CT and MR imaging of the normal and pathologic conditions of the facial nerve. European journal of radiology, 40(2), 133-146.

19. Martin, N., Sterkers, O., Mompoint, D., \& Nahum, H. (1992). Facial nerve neuromas: MR imaging. Neuroradiology, 34(1), 62-67.

20. McCarthy, W. A., \& Cox, B. L. (2014). Intraparotid schwannoma. Archives of Pathology and Laboratory Medicine, 138(7), 982-985.

21. Teresi, L. M., Lufkin, R. B., Wortham, D. G., Abemayor, E., \& Hanafee, W. N. (1987). Parotid masses: MR imaging. Radiology, 163(2), 405-409.

22. Christe, A., Waldherr, C., Hallett, R., Zbären, P., \& Thoeny, H. (2011). MR imaging of parotid tumors: typical lesion characteristics in MR imaging improve discrimination between benign and malignant disease. American Journal of Neuroradiology, 32(7), 1202-1207.

23. Alicandri-Ciufelli, M., Marchioni, D., Mattioli, F., Trani, M., \& Presutti, L. (2009). Critical literature review on the management of intraparotid facial nerve schwannoma and proposed decision-making algorithm. European archives of oto-rhinolaryngology, 266(4), 475-479.

24. Kyriakos, M. (1987). "Neurogenous tumors," in Comprehensive Management of Head and Neck Tumors, S. E. Thawley and W. R. Panje, Eds., 1253-1261, W. B. Saunders, Philadelphia, Pa, USA.

25. Humphrey, P. A., Dehner, L. P., \& Pfeifer, J. D, eds. (2012). The Washington Manual of Surgical Pathology. 2nd ed. Philadelphia, PA: Wolters Kluwer, Lippincott, Williams, and Wilkins. 
26. Johnson, J. R., Myers, E. N., \& Curtin, H. D. (1989). "Tumors of the parapharyngeal space," in Cancer of the Head and Neck, Myers, E. N., and Suen, J. Y. Eds., 669-690, Churchill Livingstone, New York, NY, USA.

27. Fine, S. W., McClain, S. A., \& Li, M. (2004). Immunohistochemical staining for calretinin is useful for differentiating schwannomas from neurofibromas. American journal of clinical pathology, 122(4), 552-559.
28. Mehta, R. P., \& Deschler, D. G. (2008). Intraoperative diagnosis of facial nerve schwannoma at parotidectomy. American journal of otolaryngology, 29(2), 126-129.

29. Ma, Q., Song, H., Zhang, P., Hou, R., Cheng, X., \& Lei, D. (2010). Diagnosis and management of intraparotid facial nerve schwannoma. Journal of Cranio-Maxillofacial Surgery, 38(4), 271-273. 